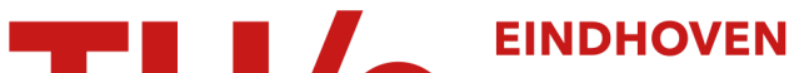 UNIVERSITY OF TECHNOLOGY
}

\section{Caesium Diffusion in Sodium Borosilicate Glass studied by Low-Energy lon Scattering}

\section{Citation for published version (APA):}

Ceelen, W. C. A. N., Jacobs, J., Brongersma, H. H., Sengers, E. G. F., \& Janssen, F. J. J. G. (1995). Caesium Diffusion in Sodium Borosilicate Glass studied by Low-Energy lon Scattering. Surface and Interface Analysis, 23(10), 712-716. https://doi.org/10.1002/sia.740231010

DOI:

10.1002/sia.740231010

Document status and date:

Published: 01/01/1995

\section{Document Version:}

Publisher's PDF, also known as Version of Record (includes final page, issue and volume numbers)

\section{Please check the document version of this publication:}

- A submitted manuscript is the version of the article upon submission and before peer-review. There can be important differences between the submitted version and the official published version of record. People interested in the research are advised to contact the author for the final version of the publication, or visit the $\mathrm{DOI}$ to the publisher's website.

- The final author version and the galley proof are versions of the publication after peer review.

- The final published version features the final layout of the paper including the volume, issue and page numbers.

Link to publication

\section{General rights}

Copyright and moral rights for the publications made accessible in the public portal are retained by the authors and/or other copyright owners and it is a condition of accessing publications that users recognise and abide by the legal requirements associated with these rights.

- Users may download and print one copy of any publication from the public portal for the purpose of private study or research.

- You may not further distribute the material or use it for any profit-making activity or commercial gain

- You may freely distribute the URL identifying the publication in the public portal.

If the publication is distributed under the terms of Article 25fa of the Dutch Copyright Act, indicated by the "Taverne" license above, please follow below link for the End User Agreement:

www.tue.nl/taverne

Take down policy

If you believe that this document breaches copyright please contact us at:

openaccess@tue.nl

providing details and we will investigate your claim. 


\title{
Caesium Diffusion in Sodium Borosilicate Glass Studied by Low-Energy Ion Scattering
}

\author{
W. C. A. N. Ceelen, * J.-P. Jacobs and H. H. Brongersma \\ Faculty of Physics and Schuit Institute of Catalysis, Eindhoven University of Technology, P.O. Box 513, 5600 MB Eindhoven, \\ The Netherlands \\ E. G. F. Sengers and F. J. J. G. Janssen \\ KEMA Nederland B.V. Business Unit Fossil Power Plants, P.O. Box 9035, 6800 ET Arnhem, The Netherlands
}

\begin{abstract}
A new, time-saving method to determine the diffusion coefficient of caesium in sodium borosilicate glass is presented. With low-energy ion scattering (LEIS) the diffusion coefficient of caesium in this glass, where the main components are the same as those in nuclear waste glass, is determined in a wide temperature range (723-849 K). Compared to the conventional concentration couple method where the diffusion has to be studied over large distances $\left(10^{5} \mathrm{~nm}\right)$, it is shown that by using LEIS accurate measurements can be performed when diffusion takes place over distances of the order of $10 \mathrm{~nm}$. Diffusion coefficients for caesium as low as $2.6 \times 10^{-22} \mathrm{~m}^{2} \mathrm{~s}^{-1}$ are extracted from the measurements. This is a factor of $10^{6}$ smaller than that measured with the concentration couple method for the same system and more than a factor of $\mathbf{1 0}$ smaller than diffusion coefficients for caesium determined in nuclear waste glasses by other techniques. At high temperatures the results of the different methods are in absolute agreement.
\end{abstract}

\section{INTRODUCTION}

Special, tailor-made, sodium borosilicate glasses are used as a storage medium for nuclear waste products such as caesium and strontium. Radioactive decay of the high-level nuclear waste leads to a temperature gradient arising in the glass. Both the temperature and the concentration gradient cause diffusion of radiotoxic elements. Eventually this could lead to a release of these elements into the biosphere. Diffusion of these elements in several nuclear waste glasses has been studied extensively, for example by Matzke et al. ${ }^{12,13}$ and Yamashita et al. $^{14}$

In earlier studies, the diffusion rate of caesium in the model nuclear waste glasses used here, has been derived by using a concentration couple. ${ }^{1,2}$ Such a couple consists of a Cs-doped and an undoped glass sample, which are melted together. During heating, caesium diffuses from the doped into the undoped part, forming a concentration profile. This profile is analysed by scanning electron microscopy combined with energy-dispersive spectrometry (SEM/EDS). To obtain reliable results, diffusion over distances of the order of $100 \mu \mathrm{m}$ is necessary. Because the diffusion process is very slow $\left(D \sim 10^{-18} \mathrm{~m}^{2} \mathrm{~s}^{-1}\right)$, diffusion has to take place at high temperatures $(>825 \mathrm{~K})$ for a long time $(\sim 500 \mathrm{~h})$. Measurements at lower temperatures are not practicable.

Actual storage, however, takes place at much lower temperatures $(400-750 \mathrm{~K})$, which is below the glass transition temperature $T_{\mathrm{g}}$ of the undoped sodium borosilicate glass $(786 \mathrm{~K})$. Because structural changes are supposed to occur in the glass at $T_{\mathrm{g}}$, extrapolation of

\footnotetext{
* Author to whom correspondence should be addressed.
}

the measured high-temperature diffusion coefficients to storage conditions is not straightforward.

To perform experiments at these low temperatures, the diffusion should be measured over distances of the order of tens of nanometres. Initial experiments described by Van Kessel et al. showed that the surface analysis technique of low-energy ion scattering (LEIS) can meet this objective. ${ }^{3}$ First, the primary ion beam of LEIS is used to create a Cs-free layer of the order of $10 \mathrm{~nm}$. Afterwards, the restoration of the caesium concentration at the surface is monitored as a function of time and temperature by the same technique but now under static conditions. From this, the diffusion coefficient can be calculated. In this paper, results are presented for a wide temperature range that extends to temperatures below the glass transition temperature.

\section{DEPLETION AND DIFFUSION}

It is known in the literature that alkali ions can be removed preferentially from glasses under ion bombardment. ${ }^{4-6}$ Because the ions have a limited penetration depth in the solid, it is possible to create a very thin alkali-depleted layer at the surface.

Miotelli and Mazzoldi ${ }^{4}$ found a depletion of sodium in soda-lime silica glass of the order of $100 \mathrm{~nm}$ for implantation with $40-50 \mathrm{keV} \mathrm{Ar}^{+}$ions. Preferential sputtering at the surface cannot account for this effect; it would only affect the outermost $1 \mathrm{~nm}$. The explanation is found in a combination of an enhanced ioninduced diffusion of the alkali ions, surface segregation of the alkali and their subsequent removal from the surface by preferential sputtering. Because neither temperature- nor electrical field-induced diffusion can account for the magnitude of the enhanced diffusion, 


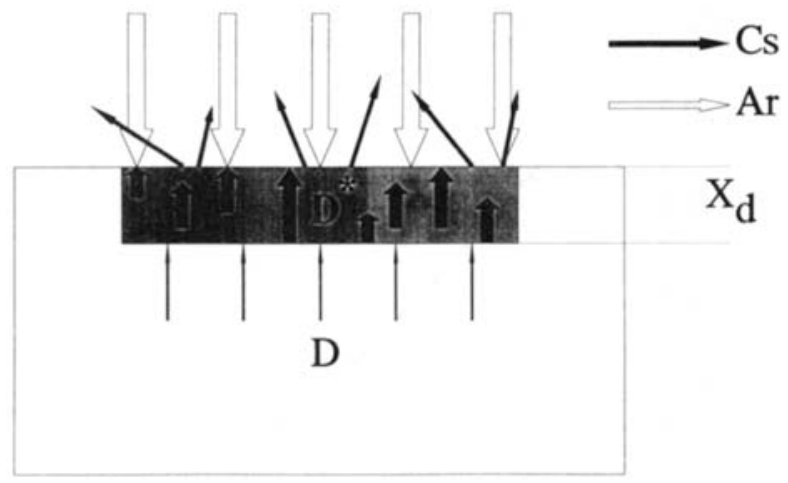

Figure 1. A schematic representation of the creation of a caesium-depleted layer by ion irradiation.

Miotelli and Mazzoldi proposed a diffusion process in the outer layer caused by an increased vacancy concentration due to the irradiation. This situation is shown schematically in Fig. 1.

The irradiation causes an enhanced diffusion of the alkali ions, and when they reach the surface they are sputtered away by the incoming ions. Because the penetration depth of the ions is limited, the enhancement is only found in a thin layer. The thickness of the layer that will be depleted can be adapted by changing the type or the energy of the incoming ion. Generally, the depletion can be determined by RBS. A depletion of 200 $\mathrm{nm}$ is found in the case of alkali silicate glasses containing $\mathrm{Na}, \mathrm{K}$ and $\mathrm{Rb}$ when bombarding the glass with 50 $\mathrm{keV} \mathrm{Ar}^{+}$ions. $^{6}$ For our purpose, a depletion of $10 \mathrm{~nm}$ of caesium in borosilicate glass is required. This distance is below the depth resolution of this system by conventional RBS, therefore, the penetration depth is estimated using the TRIM-code: Monte Carlo-type calculations to simulate the trajectories and sputtering effects of ions in matter, as described by Biersack et al. ${ }^{7}$ Combining the mean penetration depth obtained by TRIM and the results of Battaglin, ${ }^{6}$ the thickness of the depletion is estimated to be twice the mean penetration depth of the incoming ions.

After creation of the depletion layer, the ion bombardment is stopped. Then the sample is heated and diffusion will take place, caused by the concentration gradient. This caesium diffusion can be described by Fick's law [Eqn. (1)]. Assuming a step function for the concentration of caesium after the depletion treatment, one can solve this equation and obtain the diffusion coefficient $D$ fro:n Eqn. (2)

$$
\frac{\delta n(x, t)}{\delta t}=D \frac{\delta^{2} n(x, t)}{\delta x^{2}}
$$

with

$$
\begin{aligned}
n(x, 0) & =0 & & \text { for } 0<x<x_{\mathrm{D}} \\
& =n_{\infty} & & \text { for } x>x_{\mathrm{D}}
\end{aligned}
$$

which gives

$$
\frac{n_{\mathrm{t}}}{n_{\infty}}=\operatorname{erfc}\left(\frac{x_{\mathrm{D}}}{2 \sqrt{D t}}\right)
$$

Here, $n(x, t)$ represents the concentration of caesium at a given time $(t)$ and depth $(x), x_{\mathrm{D}}$ is the depletion depth, $n_{\infty}$ is the caesium concentration at the surface in thermal equilibrium and $n_{\mathrm{t}}$ is the surface caesium concentration at time $t$. The parameter $x_{\mathrm{D}}$ is derived from the TRIM calculations and it will be shown that $n_{\sqrt{ }} / n_{\infty}$ can be obtained from the LEIS measurements.

\section{EXPERIMENTAL}

\section{Equipment and samples}

In low-energy ion scattering a mono-energetic inert ion beam $(0.5-10 \mathrm{keV})$ is directed onto a target. The backscattered inert gas ions are energy selected and detected. The energy spectrum of the scattered ions provides a mass spectrum of the surface. Low-energy ion scattering is sensitive to the topmost layer only, due to the high neutralization probability of the inert gas ions and the relatively large scattering cross-section at the energies used. Recently, it has been shown that even when studying rough insulating surfaces, such as supported catalysts, LEIS can provide quantitative information on the surface composition. ${ }^{8,9}$

In the present investigation the LEIS experiments are performed with the NODUS set-up, the basic design of which has been described elsewhere. ${ }^{10}$ In its current arrangement it is possible to compensate for surface charging by flooding the surface with thermal electrons from all sides. The base pressure of the ultrahigh vacuum (UHV) system is in the high $10^{-10}$ mbar range and increases during operation to $10^{-8}$ mbar. This increase is due to the inert gas of the ion beam and does not affect the experiments. The instrument is equipped with a separate preparation chamber, which is used to heat-treat the samples. The temperatures are monitored with a pyrometer (Minolta-Land Cyclops 41). To improve the accuracy of these measurements, the backside of the disc-shaped glass samples $(10 \mathrm{~mm}$ diameter, $2 \mathrm{~mm}$ thick) is coated black with colloidal graphite (Aquadag, Agar Scientific Ltd.). ${ }^{11}$ This ensures a blackbody-like behaviour of the sample. The pyrometer is mounted normal to the surface so angular corrections for the emission coefficient are not necessary.

The Cs-doped sodium borosilicate glass has the following composition: $12 \mathrm{~mol} \% \mathrm{Na}_{2} \mathrm{O}, 25 \mathrm{~mol} \% \mathrm{~B}_{2} \mathrm{O}_{3}$ and $63 \mathrm{~mol} \% \mathrm{SiO}_{2}$ to which 2 mol.\% $\mathrm{Cs}_{2} \mathrm{O}$ has been added. Only natural (non-radioactive) caesium is used. The glasses are made by successively melting (at $1623 \mathrm{~K}$ for $2 \mathrm{~h}$ ), cooling and crushing the mixtures several times. $^{2}$ The glass transition temperature of the undoped glass is estimated at $786 \mathrm{~K}$.

\section{Measuring procedure}

As described in the section on depletion and diffusion, the diffusion coefficient can be determined by first creating a depletion layer and then measuring the amount of caesium that has diffused through that layer to the surface. This is done as a function of time. The ion dose during these measurements should be such that it does not affect the outcome of the experiment. According to earlier experiments by Van Kessel et al., ${ }^{3}$ the caesium concentration at the surface remains constant 


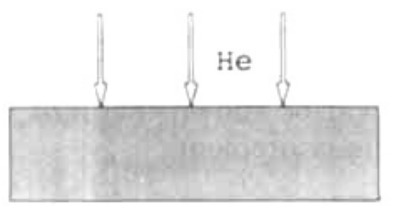

a
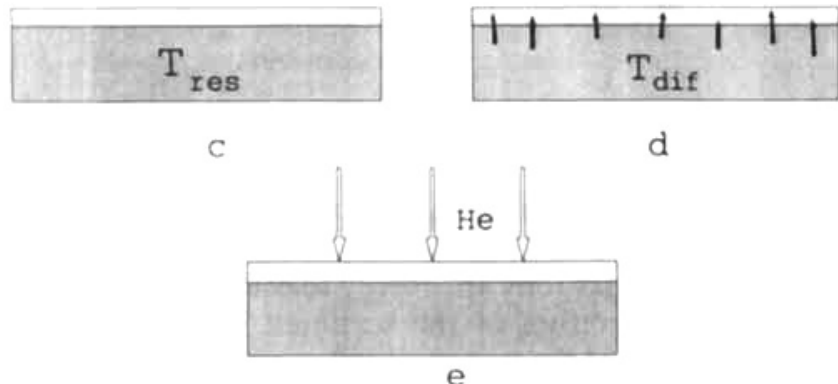

d

Figure 2. The measuring procedure with: (a) measurement of equilibrium concentration $\left(n_{\infty}\right)$; (b) creation of depletion; (c) restoration of glass matrix; (d) caesium diffusion through layer; (e) measurement of surface concentration as a function of time $\left(n_{t}\right)$.

(reduction $<5 \%$ ) when a $3 \mathrm{keV}{ }^{4} \mathrm{He}^{+}$beam with a dose $<1 \times 10^{16}$ ions $\mathrm{cm}^{-2}$ is used at room temperature. The sputtering damage of $\mathrm{Ar}^{+}$ions is $\sim 10$ times as high as that of $\mathrm{He}^{+}$ions in comparable situations.

The whole procedure is shown schematically in Fig. 2. Before the depletion is created, the initial caesium concentration $\left(n_{\infty}\right)$ is measured under static conditions [Fig. 2(a)]. Therefore, a ${ }^{4} \mathrm{He}^{+}$beam is used at room temperature $\left(D \sim 9 \times 10^{15} \mathrm{He}^{+}\right.$ions $\left.\mathrm{cm}^{-2}\right)$. Next a high-intensity $\mathrm{Ar}^{+}$beam at $500 \mathrm{~K}\left(D \sim 2 \times 10^{16} \mathrm{Ar}^{+}\right.$ ions $\mathrm{cm}^{-2}$ ) is used to create the depletion [Fig. 2(b)]. After irradiation, the glass matrix is restored by annealing at $650 \mathrm{~K}\left(T_{\text {res }}\right)$ for $\sim 2 \mathrm{~h}$ [Fig. 2(c)] and the surface composition is checked $\left(3 \mathrm{keV} \mathrm{He}{ }^{+}, T=298 \mathrm{~K}\right.$, $D<3 \times 10^{15}$ ions $\mathrm{cm}^{-2}$ ). After this analysis the sample is transported to the preparation chamber, where it is kept at the diffusion temperature $T_{\text {dif }}$ for the diffusion time $t_{\mathrm{dif}}$ [Fig. 2(d)]. Then the surface concentration of caesium $\left(n_{t}\right)$ is determined using LEIS $\left(3 \mathrm{keV} \mathrm{He}{ }^{+}\right.$, $T=298 \mathrm{~K}, D<3 \times 10^{15}$ ions $\mathrm{cm}^{-2}$ ) [Fig. 2(e)]. From a comparison of the caesium concentration at the surface of the untreated, doped sample and the treated sample, the diffusion coefficient can be extracted.

\section{RESULTS AND DISCUSSION}

To obtain depletion layers with thicknesses of 10 and 65 $\mathrm{nm}, 3 \mathrm{keV} \mathrm{Ar}{ }^{+}$and $3 \mathrm{keV} \mathrm{He}{ }^{+}$ions are used, respectively. In Fig. 3 the LEIS intensity of the Cs signal under Ar irradiation is plotted as a function of time. The caesium concentration at the surface decreases until no caesium reaches the surface; the layer is completely depleted. During the irradiation the sample is kept at $500 \mathrm{~K}$ to increase the mobility of the alkali ions, so the layer depletes faster. ${ }^{3}$ This is in agreement with the model that both diffusion and sputtering govern the process, as mentioned above.

In Fig. 4 the LEIS spectra of the sample containing 2 mol. $\% \mathrm{Cs}_{2} \mathrm{O}$ after the different treatments are shown. The different elements at the surface of the untreated

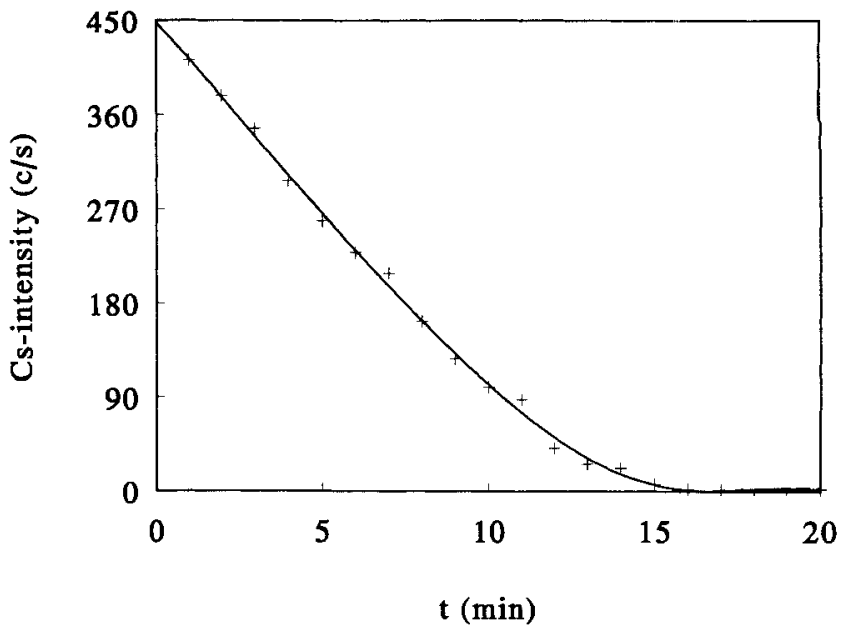

Figure 3. The signal intensity of caesium as a function of time during $3 \mathrm{keV} \mathrm{Ar}^{+}$irradiation $\left(D=1.1 \times 10^{13} \mathrm{Ar}^{+} \mathrm{cm}^{-2} \mathrm{~s}^{-1}, T=500\right.$ K).

sample can clearly be distinguished. Initial LEIS spectra showed sodium (and carbon) surface contamination that could not be removed by oxidation at mild temperature. This contamination was easily removed by light sputtering at room temperature or by heating the sample to $900 \mathrm{~K}$ in UHV. These treatments did not affect the caesium concentration at the surface. After ion irradiation at $500 \mathrm{~K}$ the sample is depleted in both $\mathrm{Cs}$ and $\mathrm{Na}$. The spectra of the sputtered and annealed surface are identical. When the sample is kept at the diffusion temperature, both $\mathrm{Na}$ and $\mathrm{Cs}$ will diffuse towards the surface under the influence of the concentration gradient. Because $\mathrm{Cs}$ diffuses much slower than $\mathrm{Na},{ }^{12}$ it diffuses through the depleted layer that then has both bulk structure and composition, including $\mathrm{Na}$. After diffusion, both $\mathrm{Na}$ and $\mathrm{Cs}$ returned to the surface.

To check if the glass matrix is restored effectively, the diffusion coefficient is measured for different diffusion

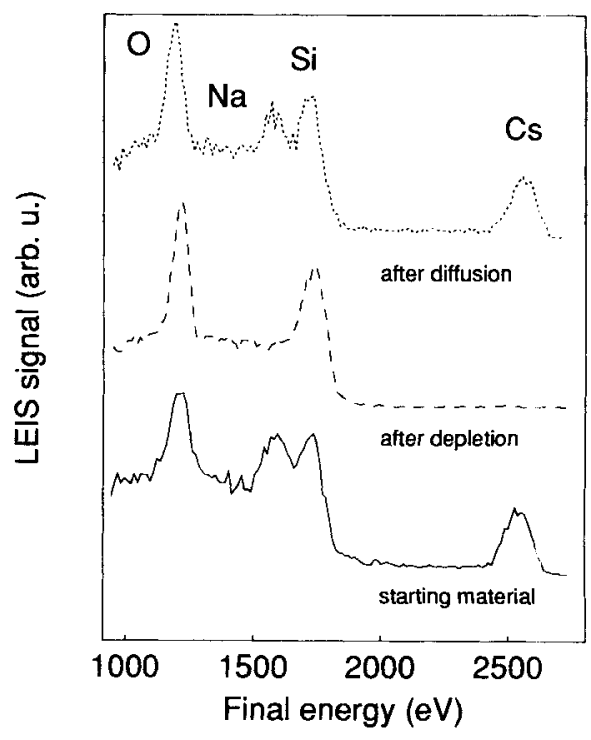

Figure 4. Characteristic set of LEIS spectra from which $n_{\infty}$ and $n_{t}$ can be derived. The depletion was created with $3 \mathrm{keV} \mathrm{Ar}^{+}$ions and the diffusion time was $86 \mathrm{~h}$ at $743 \mathrm{~K}$. The spectra were measured with $3 \mathrm{keV} \mathrm{He}^{+}$ions. 
Table 1. Experimental data and results for the determination of the diffusion coefficient measured with LEIS

\begin{tabular}{cccccc} 
Ion & $E_{\mathrm{i}}(\mathrm{keV})$ & $x_{\mathrm{d}}(\mathrm{nm})$ & $T_{\text {dif }}(\mathrm{K})$ & $t_{\text {dif }}(\mathrm{h})$ & $D\left(\mathrm{~m}^{2} \mathrm{~s}^{-1}\right)$ \\
$\mathrm{He}$ & 3 & 65 & 849 & 0.16 & $3.0 \times 10^{-18}$ \\
$\mathrm{Ar}$ & 3 & 10 & 804 & 0.20 & $1.3 \times 10^{-19}$ \\
$\mathrm{Ar}$ & 3 & 10 & 743 & $38,62,86$ & $6.7 \times 10^{-22}$ \\
$\mathrm{Ar}$ & 3 & 10 & 723 & 62 & $2.6 \times 10^{-22}$ \\
\hline
\end{tabular}

times at $T_{\text {dif }}=743 \mathrm{~K}$. If the glass matrix would not have been fully restored and, therefore, still contains a high number of vacancies, a higher diffusion coefficient after the first time interval would be measured. This is not the case. This measurement also shows that $n_{\infty}$, which is obtained at room temperature, is a good value for the equilibrium concentration at the diffusion temperature.

The results of all experiments are summarized in Table 1. When these are plotted in an Arrhenius plot, the diffusion coefficients obtained can be compared to those obtained by the concentration couple method, ${ }^{1}$ and the activation energy of the process can be determined. It should be pointed out that the numbers of the two experiments are not normalized to each other. From Fig. 5 it is clear that the absolute agreement of the two experiments is excellent. This supports the validity of the assumptions that we made: depth of depletion, step function in concentration profile, restoration of glass matrix at $T_{\text {res }}$ and $n_{\infty}$ as the equilibrium value.

Figure 5 also shows that the diffusion process does not seem to be influenced by the changing glass structure at $T_{g}$. This is in contrast to the behaviour of the viscosity, which has a higher activation energy below the glass transition temperature. This can be understood as follows. Alkali ions are network modifiers, not network formers. While viscosity is mainly influenced by the network and its network formers, diffusion of alkali through that network is not. This means that alkali diffuse through the glass while leaving the network structure intact. The activation energy for diffusion is hardly influenced by the changes in the network at $T_{\mathrm{g}}$. It is also one of the reasons why it is possible to store large quantities of radioactive waste without changing the properties of the borosilicate glass too much. It is, therefore, not evident that the diffusion of caesium should be affected by the change in structure of the glass matrix.

\section{CONCLUSIONS}

The experiments described show that the surface analysis technique of LEIS can be used to determine diffusion coefficients for specific systems. Here, it is shown that the diffusion of caesium in a model nuclearwaste glass system can be studied at temperatures where the diffusion is of the order of $10^{-22} \mathrm{~m}_{2} \mathrm{~s}^{-1}$, which is a factor of $10^{6}$ smaller than that measured with the concentration couple method. Compared to tracer diffusion measurements, ${ }^{12-14}$ the extracted values are more than a factor of 10 smaller. The improved sensitivity is obtained by following the diffusion process over distances of the order of $10 \mathrm{~nm}$ instead of $10^{5} \mathrm{~nm}$. The fact that the measured diffusion coefficients are independent of both the thickness of the depletion and the diffusion time supports the validity of the assumptions made. The LEIS procedure might also be applied to other glasses and ceramics that have been suggested for nuclearwaste storage.

For high temperatures the LEIS results are in quantitative agreement with the former experiments described by Sengers et $a l^{1}$ The Arrhenius plot shows that the activation energy $E_{\text {act }}$ of the diffusion process at low temperatures is not influenced by the structural changes at the glass transition temperature: $E_{\text {act }}=427 \pm 50 \mathrm{~kJ}$ $\mathrm{mol}^{-1}$ for the whole temperature range studied. ${ }^{2}$ This can be understood by the fact that the alkali ions are network modifiers, not network formers.

Future experiments might even reduce the diffusion time by creating the depletion with heavier noble gas

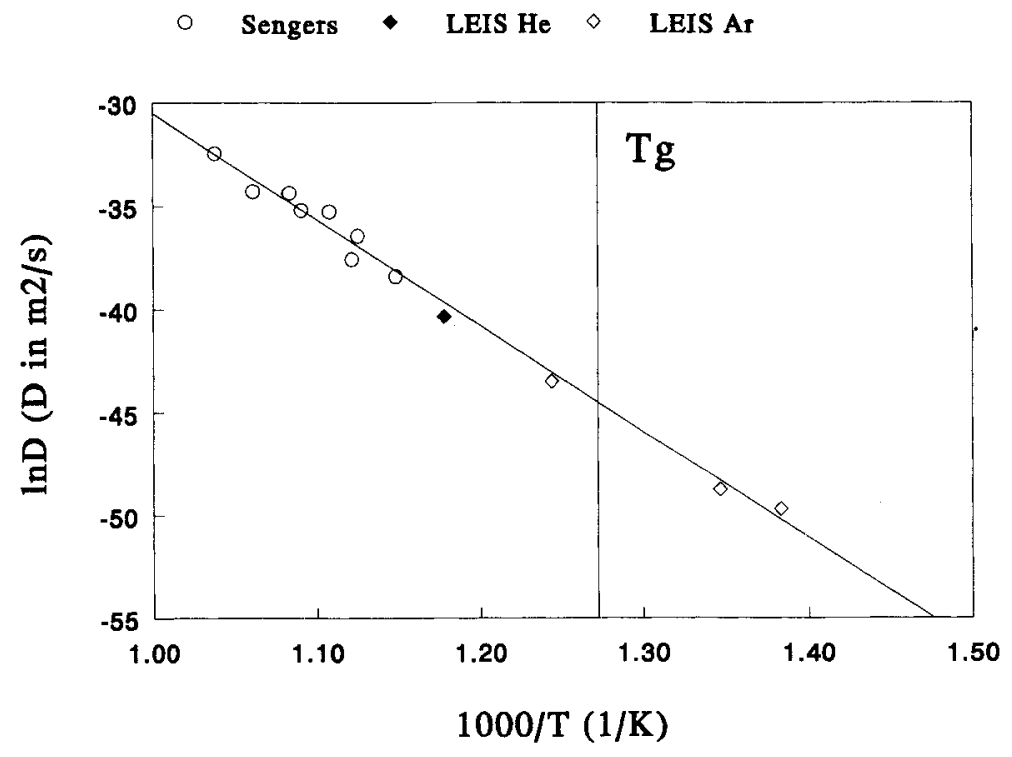

Figure 5. Arrhenius plot with both the results obtained by Sengers et al. ${ }^{1}$ and those measured with LEIS, where $T_{\mathrm{g}}$ represents the glass transition temperature. 
ions and/or a lower primary energy. Experiments at lower temperature might then be possible.

To be able to continuously monitor the surface concentration of the different elements, one might use the EARISS analyser, ${ }^{15}$ which is three orders of magnitude more sensitive than the conventional cylindrical mirror analyser used in the NODUS set-up. From these timedependent measurements one can calculate the actual concentration profile after depletion and annealing.

\section{REFERENCES}

1. E. G. F. Sengers, C. D. Andriesse, H. P. A. M. van der Staak and $\mathrm{H}$. de Waal, Kema Sci. Tech. Rep. 7, 7 (1989).

2. E. G. F. Sengers, F. J. J. G. Janssen and H. de Waal, Mater. Res. Soc. Symp. Proc. 176, 441 (1990).

3. O. van Kessel, H. H. Brongersma, J. G. A. Hölscher, R. G. van Welzenis and F. J. J. G. Janssen, Nucl. Instrum. Methods Phys. Res. B64, 593 (1992).

4. A. Miotello and P. Mazzoldi, J. Phys. C16, 221 (1983)

5. R. K. Brow, J. Vac. Sci. Technol. A7, 1673 (1989).

6. G. Battaglin, G. Della Mea, G. de Marchi, P. Mazzoldi and A. Miotello, Nucl. Instrum. Methods Phys. Res. B1, 511 (1985).

7. J. F. Ziegler, J. P. Biersack and U. Littmark, The Stopping and Range of lons in Solids. Pergamon Press, Oxford (1985).

8. H. H. Brongersma and G. C. van Leerdam, in Fundamental Aspects of Heterogeneous Catalysis Studied by Particle Beams, ed. by H. H. Brongersma and R. A. van Santen, NATO-ASI Series B265, pp. 283-300. Plenum Press, New York (1991)
9. H. H. Brongersma and J.-P. Jacobs, Appl. Surf. Sci. 75, 133 (1994).

10. H. H. Brongersma, N. Hazewindus, J. M. van Nieuwland, A M. M. Otten and A. J. Smets, Rev. Sci. Instrum. 49, 707 (1978).

11. D. R. Wheeler, W. R. Jones Jr., and S. V. Pepper, J. Vac. Sci. Technol. A6, 3166 (1988).

12. Hj. Matzke and E. Vernaz, J. Nucl. Mater. 201, 295 (1993).

13. F. Dyment, $\mathrm{Hj}$. Matzke and E. Toscano, J. Non-Cryst. Solids 93, 22 (1987).

14. M. Yamashita, R. Terai and H. Wakabayashi, J. Non-Cryst. Solids 79, 213 (1986).

15. R. H. Bergmans, W. J. Huppertz, R. G. van Welzenis and H. H. Brongersma, Nucl. Instrum. Methods Phys. Res. B64, 584 (1992). 